\title{
Standardisation of Western blotting to detect HTLV-1 antibodies synthesised in the central nervous system of HAM/TSP patients
}

\author{
Luiz Claudio Pereira Ribeiro ${ }^{1 /+}$, Cassia Cristina Alves Gonçalves ${ }^{1}$, Carla Maria Sena Andrade Slater ${ }^{1}$, \\ Silvia Maia Farias de Carvalho², Marzia Puccioni-Sohler ${ }^{1,3}$
}

\author{
1 Universidade Federal do Estado do Rio de Janeiro, Rio de Janeiro, RJ, Brasil ${ }^{2}$ Instituto Estadual de Hematologia \\ Arthur de Siqueira Cavalcanti, Rio de Janeiro, RJ, Brasil ${ }^{3}$ Universidade Federal do Rio de Janeiro, Rio de Janeiro, RJ, Brasil
}

\begin{abstract}
Intrathecal synthesis of human T-lymphotropic virus type 1 (HTLV-1) antibodies (Abs) represents conclusive evidence of a specific immune response in the central nervous system of HTLV-1 associated myelopathy/tropical spastic paraparesis (HAM/TSP) patients. Western blotting (WB) for HTLV Abs in serum is a confirmatory test for HTLV-1 infection. The aim of this study was to standardise the Western blot to demonstrate the intrathecal pattern of Abs against HTLV-1 proteins in HAM/TSP patients. Paired cerebrospinal fluid (CSF) and serum samples were selected from 20 patients with definite HAM/TSP, 19 HTLV-1 seronegative patients and two HTLV-1 patients without definite HAM/TSP. The presence of reactive bands of greater intensity in the CSF compared to serum (or bands in only the CSF) indicated the intrathecal synthesis of anti-HTLV-1 Abs. All definite HAM/TSP patients presented with an intrathecal synthesis of anti-HTLV-1 Abs; these Abs were not detected in the control patients. The most frequent intrathecal targets of anti-HTLV-1 Abs were GD21, rgp46-I and p24 and, to a lesser extent, p19, p26, p28, p32, p36, p53 gp21 and gp46. The intrathecal immune response against env (GD21 and rgp46-I) and gag (p24) proteins represents the most important humoral pattern in HAM/TSP. This response may be used as a diagnostic marker, considering the frequent association of intrathecal anti-HTLV-1 Ab synthesis with HAM/TSP and the pathogenesis of this neurological disease.
\end{abstract}

Key words: intrathecal synthesis - human T-lymphotropic virus type 1 -

HTLV-1 associated myelopathy/tropical spastic paraparesis - cerebrospinal fluid - Western blot

Human T-lymphotropic virus type 1 (HTLV-1) associated myelopathy/tropical spastic paraparesis (HAM/ TSP) is a chronic inflammatory neurologic disease of the central nervous system (CNS) that predominantly affects the spinal cord. Definitive laboratory diagnosis of HAM/TSP is based on the detection of anti-HTLV-1 antibodies (Abs) in the blood and cerebrospinal fluid (CSF) (Osame 1990, de Castro-Costa et al. 2006). However, the presence of HTLV-1 Abs in the CSF has low specificity (10-60\%) for HAM/TSP diagnosis because these Abs can be present in CSF samples from HTLV1-infected patients with other neurological diseases (Jonosono et al. 1999, Puccioni-Sohler et al. 2001). High levels of HTLV-1 Abs in the CSF may be derived from the blood or synthesised locally in the CNS. Hence, the evaluation of the intrathecal synthesis of the specific $\mathrm{Ab}$ provides an alternative approach with greater accuracy for neurological diagnosis (Reiber \& Felgenhauer 1987); this approach reflects the immune response to the viral agent (Puccioni-Sohler et al. 1999). The Western blot (WB) test exploits nitrocellulose bands con-

doi: 10.1590/0074-0276108062013009

Financial support: FAPERJ

+ Corresponding author: luizhugg@yahoo.com.br

Received 11 November 2012

Accepted 7 June 2013 taining specific native and recombinant core and envelope viral proteins. The WB test has a sensitivity of $99.9 \%$ and a specificity of $92.5 \%$ for serum analysis of HTLV-1 infection. This test has been performed on CSF without previous standardisation (Gallo et al. 1994, de Castro-Costa et al. 2006). Due to the high sensitivity and specificity and the ability to differentiate between specific viral proteins, the WB test can be valuable for assessing the intrathecal synthesis of anti-HTLV-1 Abs. In endemic areas, the use of a sensitive and specific biomarker may clarify the HAM/TSP diagnosis in mono or oligosymptomatic patients (Puccioni-Sohler et al. 2007, Slater et al. 2012). The aim of this study was to standardise the WB test (using paired CSF and serum samples) to detect specific intrathecal Abs for HAM/ TSP diagnosis.

\section{SUBJECTS, MATERIALS AND METHODS}

Samples - The CSF and serum samples analysed in this study were isolated from patients who were treated at the Neuroinfection Outpatient Clinic, Gaffrée e Guinle University Hospital (HUGG), Federal University of Rio de Janeiro State, between January 2005-February 2008. The groups were distributed as follows: group 1 contained samples from 20 patients with definite HAM/TSP according to criteria established by Osame (1990) and de Castro-Costa et al. (2006), group 2 contained seronegative HTLV-1 samples from 19 patients with other neurological diseases (multiple sclerosis, optic neuritis, SP of unknown cause, motor and sensory neuropathy, neurotuberculosis, post-viral cerebellitis, papillitis or neuro- 
toxoplasmosis) and group 3 contained samples from two patients who were seropositive for HTLV-1 [Parkinson's disease and probably HAM/TSP characterised by Babinski sign and HTLV-1 Abs in the serum and CSF, according to only the criteria by de Castro-Costa et al. (2006)].

Screening for anti-HTLV-1 Abs - All patients underwent serological screening for HTLV-1 using the ELISA method (Vironostika HTLV-1, Organon, Teknika, Durham, NC) with subsequent confirmation of the reactive cases by WB (HTLV-BLOT 2.4, MP Diagnostics, MP Biomedicals Asia Pacific Pte Ltd, Singapore). CSF samples were screened for anti-HTLV-1 Abs using the ELISA method (Vironostika HTLV-1, Organon, Teknika, Durham, NC). To interpret the WB test, samples that reacted to at least one protein from the gag gene and one protein from the env gene, including rgp46-I, were considered positive for HTLV-1.

Determination of the total $\operatorname{Ig} G$ concentration in the CSF and serum - The total IgG concentrations in the CSF and serum were determined by nephelometry (antiserum for human IgG, Dade Behring, Deerfield, Illinois, USA). The total IgG concentration of the serum divided by the total IgG concentration of the CSF determined the dilution that would be used to obtain identical concentrations of total $\mathrm{IgG}$ in the serum and CSF.

Quantitative detection of intrathecal synthesis of anti-HTLV-1 Ab - Intrathecal synthesis of anti-HTLV-1 Abs was quantitatively determined using the $\mathrm{Ab}$ index (AI) according to Reiber and Felgenhauer (1987). HTLV-1 AI $\geq 1.5$ was considered positive.

WB test to evaluate the intrathecal synthesis of antiHTLV-1 Abs - To detect the intrathecal synthesis of antiHTLV-1 Abs we applied the WB test (HTLV-BLOT 2.4, MP Diagnostics, MP Biomedicals Asia Pacific Pte Ltd, Singapore) according to the manufacturer's instructions, except in the dilution of the samples. The intrathecal synthesis of anti-HTLV-1 Abs against gag genes (p19, p24, p26, p28, p32, p36 and p53) and env genes (GD21, gp21, gp46 and rgp46-I) was analysed.

Standardisation of the sample dilutions - Serum samples were previously diluted with a buffer blotting solution to obtain concentrations identical to the total $\operatorname{IgG}$ in the CSF (Sindic et al. 2001). Dilutions of 1:2, 1:4, 1:8 and 1:16 of the CSF and serum (diluted to the same concentrations of total IgG as in the CSF) were initially used for this study. The serial dilutions were used to determine the ideal dilution for the test (the lowest possible dilution at which bands could be detected in the CSF).

Reproducibility - The protocol was repeated four times, on alternate days, with serum and CSF samples from patient H08. The tests of the serum and CSF samples from patient $\mathrm{H} 12$ were analysed at HUGG and in the lab facilities at Arthur de Siqueira Cavalcanti Hematology Institute (HEMORIO), which conducted the trial following the same protocol as used in this study.

Positivity criteria - Positive results were based on qualitative methods for the evaluation of the intrathecal synthesis of total and specific Abs (Sindic et al. 2001). The presence of bands with greater intensity in the CSF than in the serum or bands that were unique to the CSF samples was indicative of the intrathecal synthesis of the anti-HTLV-1 Abs.

Ethics - This study was analysed and approved according to the National Health Council Resolution 196/96 established by the Ethical Review Board of HUGG (project 70/2007, MEMO CEP/HUGG/013/2008).

\section{RESULTS}

Standardisation of sample dilutions and reproducibility - To obtain identical concentrations of total IgG for the CSF and serum, the sera were diluted between 68-515 times (median $=243$ ) based on the IgG concentration of each sample in group 1 . The dilutions varied from a factor of 175-820 (median $=362)$ in group 2 and the two samples in group 3 were diluted 344 and 367 times, respectively. Serial dilutions of 1:2, 1:4, 1:8 and 1:16 were used for testing the samples from patient $\mathrm{H} 08$. The best visualisation of the viral protein bands was observed using the 1:2 dilution. In this case, the following bands were more intense in the CSF sample than in the serum sample: GD21, p19/gp21, p24 and rgp46-I. The trial was repeated four times using the same samples and identical results were observed in every trial (Figure). The trial was also performed in the laboratory facilities at another institution (HEMORIO) using CSF and serum samples from patient H12. The results indicated the intrathecal synthesis of anti-HTLV-1 Abs against the same viral proteins (GD21, p19/gp21, p24, p26, p28, p32, p36, gp46, p53 and rgp46-I) as those found in the trial conducted at HUGG (Figure).

Test performance - All 20 sample pairs (CSF and serum previously diluted to the same concentrations of IgG as the CSF) from the patients with definite HAM/ TSP showed an intrathecal synthesis of Abs against at least one HTLV-1 protein (GD21, p19/gp21, p24, p26, $\mathrm{p} 28, \mathrm{p} 32, \mathrm{p} 36, \mathrm{gp} 46, \mathrm{p} 53$ or rgp46-I). The presence of bands in only the CSF occurred 26 times in 10 trials of samples from eight $(40 \%)$ patients, most frequently against the gp 46 and $\mathrm{p} 53$ proteins. One HAM/TSP sample pair (H16) displayed identical bands in both the CSF and serum with a very intense colouring, which required additional dilution of the samples. In this particular patient, dilutions of 1:4 and 1:8 revealed the presence of the intrathecal synthesis of anti-HTLV-1 Abs (more intense bands in the CSF than in the serum) against GD21, p24, p36, gp46, p53 and rgp46-I proteins, which were not evident in the 1:2 dilution. Among the 19 seronegative sample pairs belonging to patients with other neurological diseases, no reactive bands for HTLV-1 were observed in either the CSF or serum. Samples from the two patients who were seropositive for HTLV-1, but did not have definite HAM/TSP displayed weak bands that were identical in both the CSF and serum samples at a 1:2 dilution, but no evidence of the intrathecal synthesis of specific Abs was observed. Intrathecal synthesis of anti-HTLV-1 Abs was observed in all patients with definite HAM/TSP. The majority (95\%) of the HAM/TSP patients had intrathecal synthesis of anti-HTLV-1 Abs against proteins encoded by the env (GD21 or rgp46-I) and gag genes (p24) (Table). 
Higher frequency of intrathecal synthesis of HTLV-I Abs in HAM/TSP patients by $W B$ in comparison to $H T L V-1$ AI - Intrathecal synthesis of HTLV-1 Abs was analysed by WB and AI in 17 defined HAM/TSP patients. All samples displayed specific bands in the WB that were more intense in the CSF than in the serum. Thirteen $(76.5 \%)$ of the patients had HTLV-1 AI of $\geq$ 1.5 , which is indicative of specific intrathecal synthesis. Intrathecal synthesis was not detected in the two patients without definite HAM/TSP or in any of the 19 seronegative patients using either method.

\section{DISCUSSION}

This study used the WB test to assess the humoral immune pattern of the intrathecal synthesis of anti-HTLV-1 Abs. We adapted a previously established method by diluting the serum and CSF to the same concentrations of total IgG. Similar to other CSF testing methods, the appearance of more intense bands in the CSF than in the serum (or bands that appeared exclusively in the CSF) were indicative of the intrathecal synthesis of anti-HTLV-1 Abs. The WB test has previously been used to confirm the presence of anti-HTLV-1 Abs in serum and CSF (Osame et al. 1987, Ceroni et al. 1988, Gessain et al. 1988, Link et al. 1989). However, this test has not been used as a standardised qualitative method to assess the intrathecal synthesis of anti-HTLV-1 Abs (Sindic et al. 2001).

$\mathrm{HAM} / \mathrm{TSP}$ diagnosis is based on criteria established by Osame (1990) or de Castro-Costa et al. (2006). Both criteria require the demonstration of a slowly SP and the presence of anti-HTLV-1 Abs in the serum and CSF for the diagnosis of definite HAM/TSP. However, interpreting an anti-HTLV test of CSF as a support method for diagnosing HAM/TSP can be difficult due to the lack of specificity of the test. This lack of specificity results from the potential presence of anti-HTLV-1 Abs in the CSF of patients who are seropositive for HTLV-1, but do not have HAM/TSP (Nakamura et al. 1991, Kitze et al. 1996, Puccioni-Sohler et al. 2001). For this reason, establishing the origin of the Abs found in the CSF is important; the Abs
A

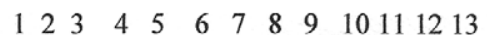

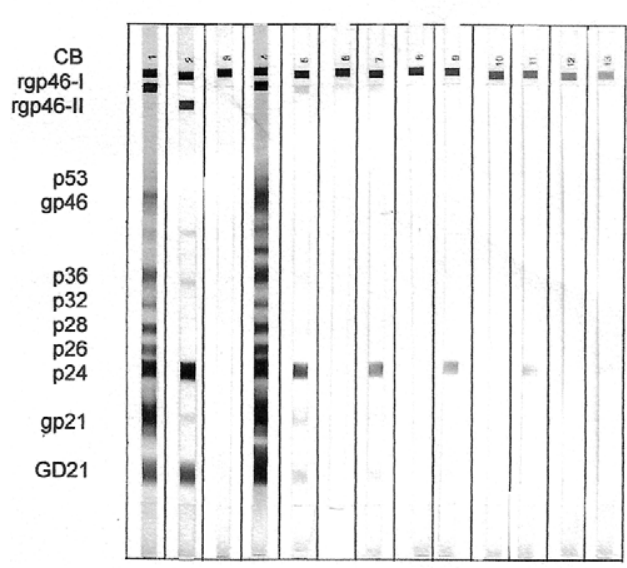

C

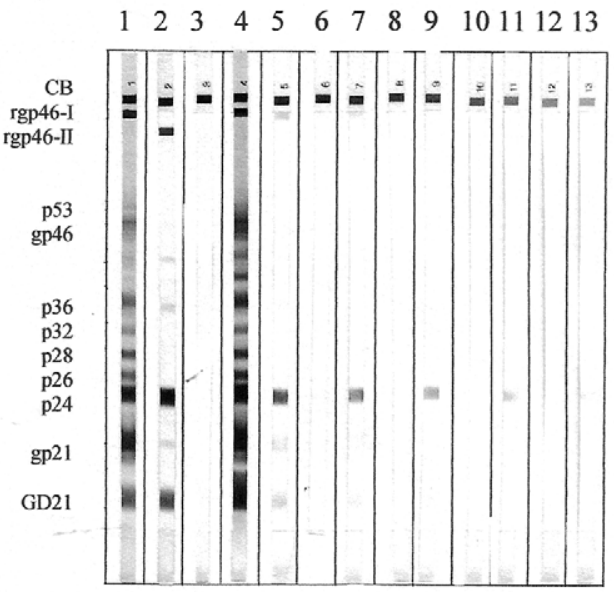

B

$\begin{array}{llllllllllllll}1 & 2 & 3 & 4 & 5 & 6 & 7 & 8 & 9 & 10 & 11 & 12 & 13\end{array}$

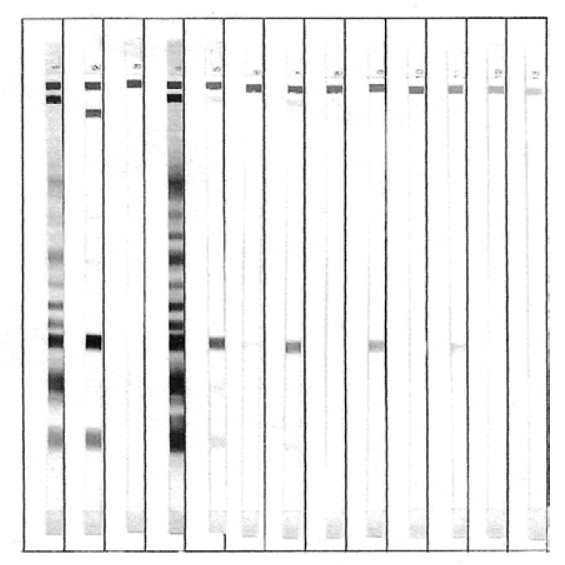

D

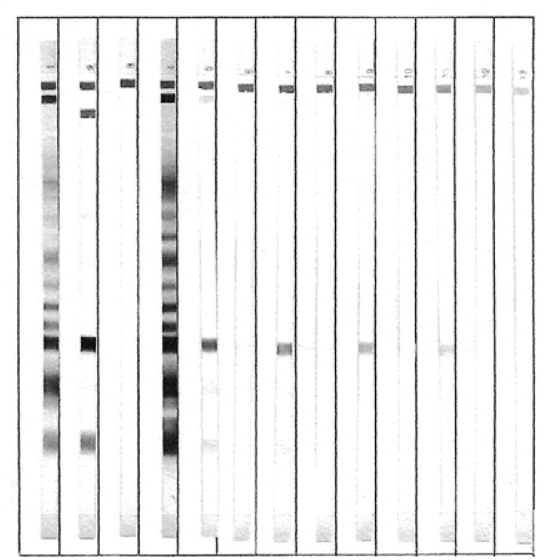

Trial repeated four times, on alternate days, in empirical dilution of 1:2, 1:4, 1:8 and 1:16 of patient H08's samples. Strip 1: positive control human T-lymphotropic virus type 1 (HTLV-1); 2: positive control HTLV-2; 3: negative control; 4, 5: serum/cerebrospinal fluid (CSF) in nature; 6, 7: serum/CSF 1:2; 8, 9: serum/CSF 1:4; 10, 11: serum/CSF 1:8; 12, 13: serum/CSF 1:16. 
can originate in the blood and cross the blood-CSF barrier or can be produced in the CSF itself. The demonstration of the intrathecal synthesis of specific Abs provides strong evidence for the presence of an immune reaction against HTLV-1 in the CSF (Puccioni-Sohler et al. 1999).

Few suggested methodologies exist for studying the intrathecal synthesis of anti-HTLV-1 Abs in patients with HAM/TSP. In the majority of studies, the sample size has been small. Intrathecal synthesis of the Abs can be demonstrated through both quantitative methods, such as the index of a specific Ab by linear correlation (Gessain et al. 1988) and hyperbolic curve (Reiber \& Felgenhauer 1987, Puccioni-Sohler et al. 1995, 2001, 2007, Kitze et al. 1996), and qualitative approaches, such as isoelectric focalisation (IEF) followed by immunofixation (Ceroni et al. 1988, Grimaldi et al. 1988, Link at al. 1989), immunoblot (McKendall et al. 1991) and radioimmunoprecipitation (RIPA) (Kitze et al. 1995). Intrathecal synthesis of specific Abs can be observed in $83 \%$ of patients with HAM/TSP using the specific AI method proposed by Reiber and Felgenhauer (1987), which is based on the ELISA test (Puccioni-Sohler et al. 2001).
Here, using the WB test, the intrathecal synthesis of specific anti-HTLV-1 Abs could be identified with higher frequency than the HTLV-1 AI in patients with definite HAM/TSP. This WB test detected Abs (including those against GD21, rgp46-I and p24) with the greatest potential to be used as markers in diagnosing HAM/TSP.

The detection of viral proteins synthesised in the CSF using the WB test may be useful for patients with possible/probable HAM/TSP (Osame 1990, de Castro-Costa et al. 2006). The intrathecal synthesis of specific antiHTLV-1 Abs was not found in patients without definite HAM/TSP based on the HTLV-1 AI and WB test. Among the qualitative methods to evaluate the intrathecal synthesis of anti-HTLV-1 Abs, RIPA of proteins from the env and gag genes (gp68 and p24, respectively) has very low sensitivity (55\%). The use of IEF followed by "in house" immunofixation to detect anti-HTLV-1 oligoclonal IgG bands requires validation for diagnostic use. The intrathecal synthesis of Abs was studied by WB for the HTLV-1 proteins p19, p24, p53, gp46 and gp68 in CSF and serum samples diluted to equal concentrations of IgG $(6 \mathrm{mg} /$ $\mathrm{mL}$ ) in only two patients. In that study, the p24 band was

TABLE

Pattern of intrathecal synthesis of human T-lymphotropic virus type 1 (HTLV-1)

antibodies (core en envelope proteins) in 20 HTLV-1 associated myelopathy/tropical spastic paraparesis (HAM/TSP) patients

\begin{tabular}{|c|c|c|c|c|c|c|c|c|c|c|c|c|c|c|c|c|c|c|c|c|}
\hline \multirow[b]{2}{*}{ Patient } & \multicolumn{2}{|c|}{ GD21 } & \multicolumn{2}{|c|}{$\mathrm{p} 19 / \mathrm{gp} 21$} & \multicolumn{2}{|c|}{$\mathrm{p} 24$} & \multicolumn{2}{|c|}{ p26 } & \multicolumn{2}{|c|}{$\mathrm{p} 28$} & \multicolumn{2}{|c|}{ p32 } & \multicolumn{2}{|c|}{ p36 } & \multicolumn{2}{|c|}{ gp46 } & \multicolumn{2}{|c|}{ p53 } & \multicolumn{2}{|c|}{ rgp46-I } \\
\hline & S & $\mathrm{C}$ & $\mathrm{S}$ & $\mathrm{C}$ & $\mathrm{S}$ & $\mathrm{C}$ & $\mathrm{S}$ & $\mathrm{C}$ & $\mathrm{S}$ & $\mathrm{C}$ & $\mathrm{S}$ & $\mathrm{C}$ & $\mathrm{S}$ & $\mathrm{C}$ & S & $\mathrm{C}$ & S & $\mathrm{C}$ & $\mathrm{S}$ & $\mathrm{C}$ \\
\hline H01 & + & ++ & + & ++ & + & ++ & + & ++ & + & ++ & 0 & ++ & + & ++ & 0 & ++ & 0 & ++ & + & ++ \\
\hline H02 & + & ++ & + & ++ & + & ++ & + & ++ & + & ++ & + & ++ & + & ++ & + & ++ & + & ++ & + & ++ \\
\hline H03 & + & ++ & + & + & + & ++ & + & + & + & + & 0 & 0 & + & + & 0 & 0 & 0 & 0 & + & ++ \\
\hline H04 & 0 & ++ & + & + & + & ++ & 0 & 0 & 0 & 0 & 0 & 0 & 0 & 0 & 0 & 0 & 0 & 0 & + & ++ \\
\hline H05 & + & ++ & + & ++ & + & ++ & + & ++ & + & ++ & + & ++ & + & ++ & 0 & ++ & 0 & ++ & + & ++ \\
\hline H06 & + & ++ & + & ++ & + & ++ & + & ++ & + & ++ & 0 & ++ & + & ++ & 0 & 0 & 0 & ++ & + & ++ \\
\hline H07 & 0 & ++ & + & ++ & + & ++ & 0 & ++ & 0 & ++ & 0 & ++ & 0 & 0 & 0 & ++ & 0 & 0 & + & ++ \\
\hline H08 & + & ++ & + & ++ & + & ++ & 0 & ++ & 0 & ++ & 0 & 0 & 0 & ++ & 0 & 0 & 0 & 0 & + & ++ \\
\hline H09 & + & ++ & + & ++ & + & ++ & + & ++ & + & ++ & + & ++ & + & ++ & 0 & ++ & 0 & ++ & + & ++ \\
\hline H10 & + & ++ & + & + & + & ++ & + & + & + & + & + & + & + & + & + & + & + & + & + & + \\
\hline H11 & + & + & + & + & + & + & + & + & + & + & + & + & + & + & + & + & + & + & + & ++ \\
\hline H12 & + & ++ & + & ++ & + & ++ & + & ++ & + & ++ & + & ++ & + & ++ & 0 & ++ & 0 & ++ & + & ++ \\
\hline H13 & + & ++ & + & ++ & + & ++ & + & ++ & + & ++ & + & ++ & + & ++ & 0 & ++ & 0 & ++ & + & ++ \\
\hline H14 & + & ++ & + & ++ & + & ++ & + & + & + & ++ & + & + & + & ++ & 0 & ++ & 0 & ++ & + & ++ \\
\hline H15 & + & ++ & + & + & + & ++ & + & + & + & + & + & + & + & + & 0 & 0 & + & + & + & ++ \\
\hline H16 & + & ++ & + & + & + & ++ & + & + & + & + & + & + & + & ++ & + & ++ & + & ++ & + & ++ \\
\hline H17 & + & ++ & + & ++ & + & ++ & + & ++ & + & ++ & + & ++ & + & ++ & + & ++ & + & ++ & + & ++ \\
\hline H18 & + & ++ & + & ++ & + & ++ & + & ++ & + & ++ & + & ++ & + & ++ & + & ++ & + & ++ & + & ++ \\
\hline H19 & + & ++ & + & + & + & ++ & + & + & + & + & + & + & + & ++ & 0 & ++ & 0 & ++ & + & ++ \\
\hline $\mathrm{H} 20$ & + & ++ & + & ++ & + & ++ & + & ++ & + & ++ & + & ++ & + & ++ & + & ++ & + & ++ & + & ++ \\
\hline $\begin{array}{l}\text { Patients with } \\
\text { intrathecal synthesis } \\
\text { of HTLV-1 Ab (n) }\end{array}$ & & & & 3 & & & & & & & & 1 & & 5 & & 2 & & 3 & & 9 \\
\hline
\end{tabular}

Ab: antibody; C: cerebrospinal fluid; reference for intrathecal synthesis of HTLV-1 antibodies: presence of bands only in CSF or higher intensity in CSF than in serum; S: serum; 0: no band; +: weak band; ++: intense band. 
detected at greater intensity in the CSF than in the serum, which is compatible with the intrathecal synthesis of the $\mathrm{Ab}$ against this specific protein (Link at al. 1989). In our study, the intrathecal synthesis of anti-HTLV-1 Abs against the protein from one viral gene was observed in all patients with definite HAM/TSP. The intrathecal synthesis of Abs against proteins from two viral genes, env (GD21 or rgp-46-I) and gag (p24), was observed in 95\% of patients. Abs against the following proteins were also observed less frequently: p36 (75\%), p53, p19/gp21 and p28 (65\%), gp46 and p26 (60\%) and p32 (55\%).

In $95 \%$ of the patients (19/20), the intrathecal synthesis of anti-HTLV-1 Abs was observed in 1:2 dilutions of paired CSF and serum and only $5 \%$ of cases $(1 / 20)$ required additional dilutions to demonstrate intrathecal synthesis.

This study of the WB test to detect the intrathecal synthesis of Abs against HTLV-1 was reproducible and easily employed. The intrathecal humoral immune pattern in definite HAM/TSP patients included Abs against viral HTLV-1 proteins from the gag (p19, p24, p26, p28, p32, p36, p53) and env (GD21, gp21, gp46, rgp46-I) genes. The viral proteins from the GD21, rgp46-I and p24 genes have the greatest antigenic potential in the CNS. The high frequency of an intrathecal immune response against different HTLV-1 proteins may be associated with the pathogenesis of this neurological disease and can be exploited in a specific laboratory test for the diagnosis of HAM/TSP.

\section{ACKNOWLEDGEMENTS}

To Dr Derliane Oliveira, for her contribution in the quality protocol of this study.

\section{REFERENCES}

Ceroni M, Piccardo P, Rodgers-Johnson P, Mora C, Asher DM, Gajdusek DC, Gigg Jr CJ 1988. Intrathecal synthesis of IgG antibodies to HTLV-I supports an etiological role for HTLV-I in tropical spastic paraparesis. Ann Neurol 23 (Suppl.): S188-S191.

de Castro-Costa CM, Araújo AQ, Barreto MM, Takayanagui OM, Sohler MP, da Silva EL, de Paula SM, Ishak R, Ribas JG, Rovirosa LC, Carton H, Gotuzzo E, Hall WW, Montano S, Murphy EL, Oger J, Remondegui C, Taylor GP 2006. Proposal for diagnostic criteria of tropical spastic paraparesis/HTLV-I-associated myelopathy (TSP/HAM). AIDS Res Hum Retroviruses 22: 931-935.

Gallo D, Diggs JL, Hanson CV 1994. Evaluation of two commercial human T-cell lymphotropic virus western blot (immunoblot) kits with problem specimens. J Clin Microbiol 32: 2046-2049.

Gessain A, Caudie C, Gout O, Vernant JC, Maurs L, Giordano C, Malone G, Tournier-Lasserve E, Essex M, de-Thé G 1988. Intrathecal synthesis of antibodies to human T lymphotropic virus type $\mathrm{I}$ and the presence of $\mathrm{IgG}$ oligoclonal bands in the cerebrospinal fluid of patients with endemic tropical spastic paraparesis. J Infect Dis 157: 1226-1234.

Grimaldi LM, Roos RP, Devare SG, Casey JM, Maruo Y, Hamada T, Tashiro K 1988. HTLV-I-associated myelopathy: oligoclonal immunoglobulin bands contain anti-HTLV-I p24 antibody. Ann Neurol 24: 727-731.
Jonosono M, Matsusaki T, Usuku K, Nakagawa M, Osame M 1999. Evaluation of usefulness of anti-HTLV-1 antibody titer measurement in the spinal fluid for establishing diagnosis of HAM/TSP. J Acquir Immune Defic Syndr (Suppl.) 20: 133.

Kitze B, Puccioni-Sohler M, Schäffner J, Rieckmann P, Weber T, Felgenhauer K, Bodemer W 1995. Specificity of intrathecal IgG synthesis for HTLV-I core and envelope proteins in HAM/TSP. Acta Neurol Scand 92: 213-217.

Kitze B, Usuku K, Izumo S, Nakamura M, Shiraki H, Ijichi S, Yashiki S, Fujiyoshi T, Sonoda S, Osame M 1996. Diversity of intrathecal antibody synthesis against HTLV-I and its relation to HTLV-I associated myelopathy. J Neurol 243: 393-400.

Link H, Cruz M, Gessain A, Gout O, de Thé G, Kam-Hansen S 1989. Chronic progressive myelopathy associated with HTLV-I: oligoclonal IgG and anti-HTLV-I IgG antibodies in cerebrospinal fluid and serum. Neurology 39: 1566-1571.

McKendall RR, Oas J, Laimore MD 1991. HTLV-I-associated myelopathy endemic in Texas-born residents and isolation of virus from CSF cells. Neurology 4: 831-836.

Nakamura M, Kuroki M, Kira J, Itoyama Y, Shiraki H, Kuroda N, Washintani Y, Nakano S, Nagafuchi S, Anzai K 1991. Elevated antibodies to synthetic peptides of HTLV-I envelope transmembrane glycoproteins in patients with HAM/TSP. J Neuroimmunol 35: 167-177.

Osame M 1990. Review of WHO Kagoshima Meeting and Diagnostic Guidelines for HAM/TSP. In WA Blattner (ed.), Human retrovirology: HTLV, Raven Press, New York, p. 191-197.

Osame M, Matsumoto M, Usuku K, Izumo S, Ijichi N, Amitani H, Tara M, Igata A 1987. Chronic progressive myelopathy associated with elevated antibodies to human T-lymphotropic virus type I and adult T-cell leukemia like cells. Ann Neurol 21: 117-122.

Puccioni-Sohler M, Kitze B, Felgenhauer K 1995. HTLV-I associated myelopathy in patients from Brazil and Iran: neurological manifestations and cerebrospinal fluid findings. Arq Neuropsiquiatr 53: 213-217.

Puccioni-Sohler M, Rios M, Bianco C, Zhu SW, Oliveira C, Novis SA, Pombo-de-Oliveira MS 1999. An inverse correlation of HTLV-I viral load in CSF and intrathecal synthesis of HTLV-I antibodies in TSP/HAM. Neurology 53: 1335-1339.

Puccioni-Sohler M, Rios M, Carvalho SM, Gonçalves RR, Oliveira C, Correa RB, Novis SA, de Oliveira MS, Bianco C 2001. Diagnosis of HAM/TSP based on CSF proviral HTLV-I DNA and HTLV-I antibody index. Neurology 57: 725-727.

Puccioni-Sohler M, Yamano Y, Rios M, Carvalho SM, Vasconcellos CC, Papais-Alvarenga R, Jacobson S 2007. Differentiation of HAM/TSP from patients with multiple sclerosis infected with HTLV-I. Neurology 68: 206-213.

Reiber H, Felgenhauer K 1987. Protein transfer at the blood cerebrospinal fluid barrier and the quantification of the humoral immune response within the central nervous system. Clin Chem Acta 163: 319-328.

Sindic CJ, Van Antwerpen MP, Goffette S 2001. The intrathecal humoral immune response: laboratory analysis and clinical relevance. Clin Chem Lab Med 39: 333-340.

Slater CMSA, Ribeiro LCP, Puccionni-Soheler M 2012. Difficulties in HAM/TSP diagnosis. Arq Neuro-Psiquiatr 70: 686-690. 